\title{
Cytomegaloviruses inhibit Bak- and Bax-mediated apoptosis with two separate viral proteins
}

\author{
M Çam ${ }^{1}$, W Handke ${ }^{1}$, M Picard-Maureau² and W Brune ${ }^{\star, 1}$
}

Apoptosis of infected cells can limit virus replication and serves as an innate defense mechanism against viral infections. Consequently, viruses delay apoptosis by expressing antiapoptotic proteins, many of which structurally resemble the cellular antiapoptotic protein Bcl-2. Like Bcl-2, the viral analogs inhibit apoptosis by preventing activation and/or oligomerization of the proapoptotic mitochondrial proteins Bax and Bak. Here we show that cytomegaloviruses (CMVs) have adopted a different strategy. They encode two separate mitochondrial proteins that lack obvious sequence similarities to Bcl-2-family proteins and specifically counteract either Bax or Bak. We identified a small mitochondrion-localized protein encoded by the murine CMV open reading frame (ORF) m41.1, which functions as a viral inhibitor of Bak oligomerization (vIBO). It blocks Bak-mediated cytochrome $c$ release and Bak-dependent induction of apoptosis. It protects cells from cell death-inducing stimuli together with the previously identified Bax-specific inhibitor viral mitochondria-localized inhibitor of apoptosis (vMIA) (encoded by ORF m38.5). Similar vIBO proteins are encoded by CMVs of rats, and possibly by other CMVs as well. These results suggest a non-redundant function of Bax and Bak during viral infection, and a benefit for CMVs derived from the ability to inhibit Bak and Bax separately with two viral proteins.

Cell Death and Differentiation (2010) 17, 655-665; doi:10.1038/cdd.2009.147; published online 9 October 2009

Programmed cell death (PCD) or apoptosis has numerous functions in a multicellular organism. It is important during development, for maintenance of tissue homeostasis, for elimination of damaged or transformed cells, and as a first line of defense against infectious agents. The cellular suicide program can be particularly effective as an antiviral defense mechanism, since viruses depend on the host cell for replication. ${ }^{1}$ Viral dissemination can be severely impaired if an infected cell executes apoptosis before the viral replication cycle is completed. The importance of apoptosis is underscored by the fact that many viruses have evolved genes encoding antiapoptotic proteins. ${ }^{2}$

Viral infection and replication exert different kinds of stress on the host cell: depletion of nutrients, impairment of cellular protein biosynthesis, induction of the unfolded protein response (also called endoplasmic reticulum stress), and a DNA-damage response. All kinds of stress can initiate signaling pathways culminating in apoptosis. ${ }^{2}$ Caspases, a group of aspartate-specific cysteine proteases, are pivotal signal transducers within apoptotic signaling cascades, whose activation is regulated by proteins of the Bcl-2 family. ${ }^{3}$ This family consists of pro- and antiapoptotic members, which differ in the number of $\mathrm{Bcl}-2$ homology $(\mathrm{BH})$ domains. According to the current model, antiapoptotic Bcl-2-family proteins prevent caspase activation by preserving mitochon- drial integrity. ${ }^{3}$ The activity of the antiapoptotic $\mathrm{Bcl}-2$ proteins is antagonized by the proapoptotic multidomain proteins Bax and Bak, and the so-called BH3-only proteins, which posses only the third out of four $\mathrm{BH}$ domains. In response to apoptotic stimuli, the $\mathrm{BH}$-only proteins translocate to mitochondria where they counteract the function of pro-survival $\mathrm{Bcl}-2$ proteins and activate the proapoptotic proteins Bax and Bak. $^{4}$ The monomeric proteins undergo a conformational change, oligomerize, and increase the permeability of the mitochondrial outer membrane. ${ }^{5}$ This leads to release of cytochrome $c$ (cyt $c$ ) into the cytosol and subsequent activation of caspases. The release of other mitochondrial proteins such as apoptosis-inducing factor (AIF), Smac/ DIABLO, Htr2A/Omi, and endonuclease-G also contributes to the execution of PCD. ${ }^{4}$ Earlier studies have shown that Bak and Bax function in a largely redundant manner during development ${ }^{6}$ and in response to various apoptosis inducers. ${ }^{5}$ However, more recent results indicated that the two proteins also fulfill some non-redundant functions. ${ }^{7-10}$

A number of viruses, particularly adenoviruses and $\gamma$-herpesviruses, express proteins homologous to the cellular antiapoptotic proteins $\mathrm{Bcl}-2$ and $\mathrm{BCl}-\mathrm{x}_{\mathrm{L}} .{ }^{2,11}$ Poxviruses also express apoptosis inhibitors that resemble $\mathrm{Bcl}-\mathrm{x}_{\mathrm{L}}$ in their three-dimensional structure, even though their amino-acid sequences are not homologous. ${ }^{12,13}$ Like Bcl- $\mathrm{X}_{\mathrm{L}}$,

\footnotetext{
${ }^{1}$ Division of Viral Infections, Robert Koch Institute, Nordufer 20, 13353 Berlin, Germany and ${ }^{2}$ Department of Virology, Institute of Medical Microbiology and Hygiene, University Hospital Mannheim, Theodor-Kutzer-Ufer 1-3, 68167 Mannheim, Germany

*Corresponding author: Dr W Brune, Division of Viral Infections, Robert Koch Institute, Nordufer 20, 13353 Berlin, Germany. Tel: +49 30187542502 ;

Fax: + 49301810754 2502; E-mail: BruneW@ rki.de

Keywords: apoptosis; cytomegalovirus; m41.1; Bak; Bax

Abbreviations: ActD, actinomycin-D; BAC, bacterial artificial chromosome; BH, Bcl-2 homology; BMH, 1', $6^{\prime}$-bismaleimidohexane; CMV, cytomegalovirus; DAPI, $4^{\prime}, 6^{\prime}$ diamidino-2-phenylindole; ER, endoplasmic reticulum; FRT, FLP recombination target site; HCMV, human cytomegalovirus; hpi, hours postinfection; MCMV, murine cytomegalovirus; MOI, multiplicity of infection; MTT, 3-(4,5-dimethylthiazol-2-yl)-2,5-diphenyltetrazolium bromide; nt, nucleotide(s); ORF, open reading frame; PCD, programmed cell death; RCMV, rat cytomegalovirus; STS, staurosporine; TCID $_{50}$, median tissue culture infective dose; TUNEL, terminal deoxynucleotidyltransferasemediated dUTP-biotin nick-end-labeling; vIBO, viral inhibitor of Bak oligomerization; vMIA, viral mitochondria-localized inhibitor of apoptosis; wt, wild type

Received 07.4.09; revised 14.8.09; accepted 10.9.09; Edited by JM Hardwick; published online 9.10.09
} 
these viral proteins inhibit both Bax- and Bak-mediated cell death.

A different strategy to inhibit apoptosis at the mitochondrial checkpoint is pursued by cytomegaloviruses (CMVs). Human CMV encodes a viral mitochondrion-localized inhibitor of apoptosis (VMIA, encoded by open reading frame (ORF) UL37x1) that interacts with Bax and specifically inhibits Bax-mediated cell death. ${ }^{14-16}$ The primary structure of human CMV (HCMV) VMIA has no obvious similarities to Bcl-2-family proteins, ${ }^{14}$ but an in silico structural analysis predicted a fold similar to $\mathrm{Bcl}-\mathrm{x}_{\mathrm{L}}{ }^{17}$ Murine CMV (MCMV) also expresses a VMIA protein, which is encoded at an analogous position within the viral genome by ORF m38.5, but displays little sequence similarity to HCMV VMIA. ${ }^{18,19}$ The MCMV m38.5 protein inhibits Bax-but not Bak-mediated apoptosis, ${ }^{20-22}$ and also induces mitochondrial fragmentation in the absence of Bak (i.e., in bak ${ }^{-1-}$ cells). ${ }^{23}$ Moreover, the observation that MCMV-infected cells are protected from Bax- and Bakmediated apoptosis suggested that the virus encodes an additional, Bak-specific antiapoptotic protein. ${ }^{20}$

In the present study, we identified the product of MCMV ORF m41.1 as a Bak-specific inhibitor of apoptosis. The m41.1 protein localizes to mitochondria and prevents Bak oligomerization, cyt $c$ release, and execution of PCD. In conjunction with the m38.5/vMIA protein, it protects infected cells from apoptosis induced by cytotoxic drugs or the viral infection itself. Moreover, structurally and functionally similar proteins are encoded by rat CMVs. The unusual ability of CMVs to block Bax and Bak with two separate proteins suggests that it might be advantageous for these viruses to modulate Bax- and Bak-dependent pathways separately. The identification of these two viral inhibitors should provide new insights into the differential importance of the two proapoptotic $\mathrm{Bcl}-2$ family members in viral infection-induced cell death.

\section{Results}

Identification of the protein expressed by $\mathrm{m41.1}$. We identified ORF $\mathrm{m} 41$ as a region of the MCMV genome encoding an antiapoptotic protein in a previous study. ${ }^{24}$ Deletion of the m41 ORF from the MCMV genome resulted in premature death of infected cells that could be reduced by addition of broad-spectrum caspase inhibitors. The m41 protein was shown to localize to the Golgi apparatus, but its mechanism of action has remained undefined.

A recent computational re-annotation of the MCMV genome revealed the presence of a second ORF embedded within $\mathrm{m} 41$ in a different reading frame. ${ }^{18}$ This ORF was named m41.1 and has the potential to code for a 57-amino-acid protein (Figure 1a and $\mathrm{c}$ ). The putative start codon is located 10 nucleotides (nt) downstream of the m41 translational start. A predominant transcript of approximately $0.6 \mathrm{~kb}$ was identified by Northern blot analysis (Figure $1 \mathrm{~b}$ ). The $5^{\prime}$ and $3^{\prime}$ ends of the mRNA transcripts were determined by rapid amplification of CDNA ends (RACE). The major transcript starts at nt position 54227 of the MCMV genome and terminates at position 53680, 93-nt downstream of the m41 ORF and 21-nt downstream of a canonical AATAAA polyadenylation signal. Several larger transcripts of low abundance (Figure 1b) were also cloned and sequenced. All of them used a splice acceptor site at position 54217 (Figure 1a), but none of them had the capacity to encode an N-terminally extended m41 or m41.1 protein (data not shown). Hence we concluded that the m41 and $\mathrm{m} 41.1$ gene products must be translated from the same 0.6-kb mRNA transcript by using the first or one of the following start codons.

We have previously shown that the m41 ORF is expressed during MCMV infection and translated into a protein of 138 amino acids with an apparent molecular mass of approximately $20 \mathrm{kDa}^{24}$ To determine whether an m41.1 protein is also synthesized during MCMV infection, we inserted an HA epitope tag sequence and a selectable marker (kan) at the $3^{\prime}$ end of the m41.1 ORF (Figure 1c). This procedure leaves the transcriptional and translational start sites of $\mathrm{m} 41.1$ unchanged, and is, therefore, unlikely to affect the expression pattern of $\mathrm{m} 41.1$. We detected the HA-tagged $\mathrm{m} 41.1$ protein in lysates of infected 10.1 fibroblasts by Western blotting starting about 5 hpi (Figure 1d). Further experiments showed that m41.1 was expressed in the presence of a DNA-synthesis inhibitor, but not after release from the cytoheximide block (Supplementary Figure S1A). Hence m41.1 can be classified as an early gene product. The protein had an apparent molecular mass of approximately $7 \mathrm{kDa}$ (not shown), which corresponds to its predicted mass.

Functional dissection of the m41 locus. In order to determine whether $\mathrm{m} 41, \mathrm{~m} 41.1$, or both gene products are responsible for the previously described antiapoptotic activity, we constructed mutant viruses lacking m41.1, m41, or both ORFs (Figure 1c). In the $\Delta \mathrm{m} 41$ mutant, the m41 ORF was replaced with a zeocin-resistance gene. To construct an m41.1-knockout mutant (m41.1ko), we introduced three silent mutations into the m41 ORF, which eliminated the three potential ATG start codons of m41.1 (Figure 1a). The m41ko virus was constructed by inserting the m41.1 ORF at an ectopic position into the genome of the $\Delta \mathrm{m} 41$ mutant. In a similar way, two genes encoding well-characterized mitochondrial apoptosis inhibitors were inserted: the cellular $\mathrm{Bcl}-\mathrm{x}_{\mathrm{L}}$ and the myxoma virus $\mathrm{Bcl}-2$ analog M11L. ${ }^{12,25}$ The integrity of the constructed mutants was determined by restriction-fragment length analysis and by immunoblotting (Supplementary Figure S1B-D).

As our previous work has shown that the $\Delta \mathrm{m} 41$ mutant induced apoptosis of infected cells, ${ }^{24}$ we first analyzed how the newly constructed mutants affected the viability of infected cells. Murine 10.1 fibroblasts were infected with the mutant viruses at a high multiplicity of infection (MOI), and cell viability was determined using an MTT (3-(4,5-dimethylthiazol-2-yl)2,5-diphenyltetrazolium bromide) assay. Fibroblasts infected with $\Delta \mathrm{m} 41$ or $\mathrm{m} 41.1 \mathrm{ko}$ showed clearly reduced viability at 72 hpi (Figure 2a). By contrast, the viability of cells infected with m41ko or $\Delta \mathrm{m} 41 / \mathrm{M} 11 \mathrm{~L}$ was similar to those infected with the wild-type (wt) virus, suggesting that the $\mathrm{m} 41$ protein is not required to inhibit premature $P C D$ in fibroblasts. We also infected RAW264.7 macrophages, which are more sensitive to virus-induced PCD. At 18 hpi their viability was reduced after infection with wt MCMV and even more with $\Delta \mathrm{m} 41$, m41ko, or m41.1ko (Figure $2 \mathrm{~b}$ and Supplementary Figure S2). Similar results were obtained with IC-21 macrophages 


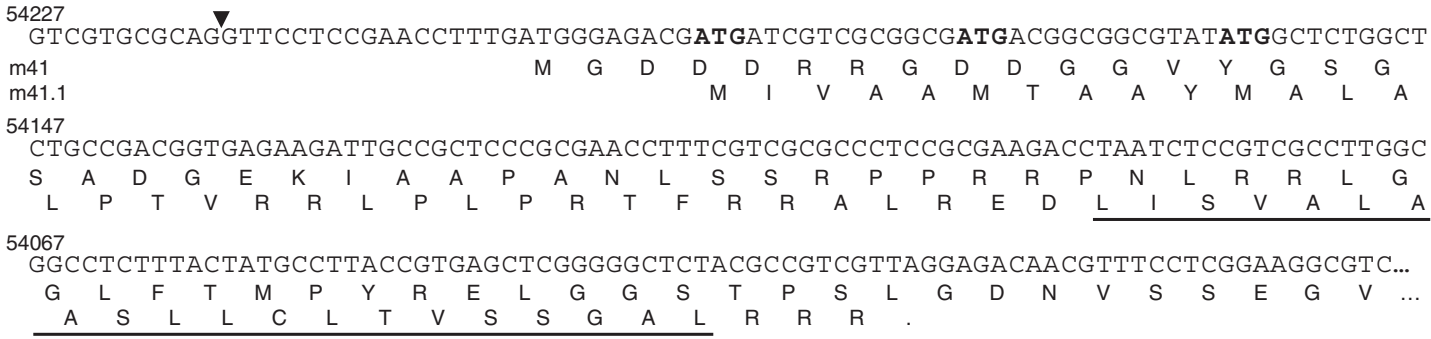

b

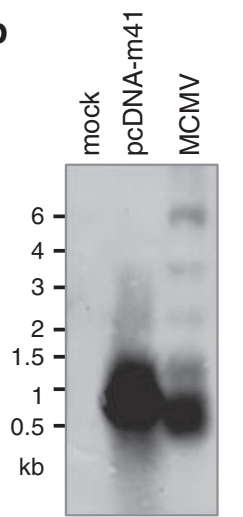

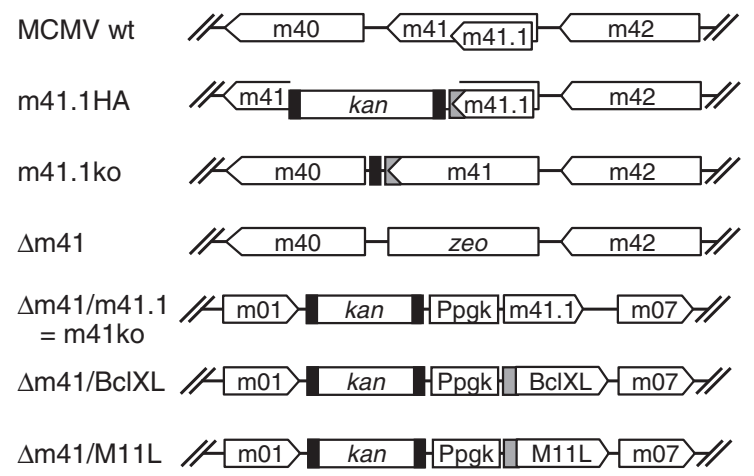

d

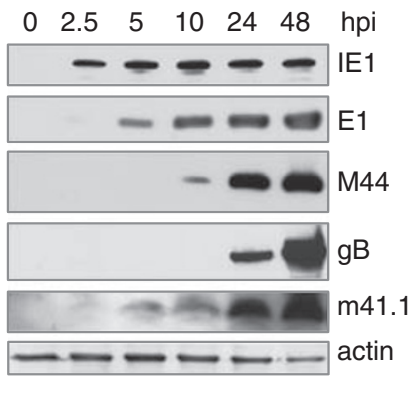

Figure 1 Transcriptional analysis and mutagenesis of the m41 locus. (a) The major transcript starts at nt position 54227 and is cleaved and polyadenylated after nt position 53680 . Two protein products encoded in different reading frames are translated from this transcript: the 138-amino-acid m41 (upper translation) and the 57-aminoacid $\mathrm{m} 41.1$ (lower translation) proteins. Three possible $\mathrm{m} 41.1$ start codons are shown in bold and the predicted transmembrane domain is underlined. Note that only the first 70 amino acids of $\mathrm{m} 41$ are shown. (b) Northern blot analysis of $\mathrm{m} 41$ transcripts. In addition to the major transcript, a few larger, low-abundance transcripts are detectable, which are spliced transcripts initiating upstream of $\mathrm{m} 41$. They use the splice acceptor site indicated by an arrowhead in panel a. Transcripts of similar size are detected in cells transfected with pcDNA-m41. (c) Schematic view of the m41 locus within the MCMV genome. The m41.1 ORF was tagged within the viral genome with an HA epitope tag sequence (grey box), resulting in disruption of the m41 ORF. In the previously described $\Delta \mathrm{m} 41$ mutant, the m41 ORF was replaced with a zeocin-resistance marker. ${ }^{24}$ The $\mathrm{m} 41.1 \mathrm{ko}$ mutant was obtained by re-inserting an HA-tagged version of $\mathrm{m} 41$, in which the $\mathrm{m} 41.1$ ATGs had been mutated to ACG. Based on $\triangle \mathrm{m} 41$, three additional mutants were constructed by inserting ORFs m41.1, HA-Bcl- $\mathrm{x}_{\mathrm{L}}$, or FlagM11L driven by a phosphoglycerate kinase promoter $\left(\mathrm{P}_{\text {pgk }}\right)$ into the nonessential m02-m06 region of the MCMV genome. (d) The HA-tagged m41.1 protein was detected in cells infected with MCMV-m41.1HA by Western blot starting 5 hpi. The immediate-early- 1 protein (IE1), the early-1 protein (E1), the M44 protein, and glycoprotein-B (gB) are shown as representatives of the immediate-early, early, early-late, and late kinetic classes of MCMV proteins

(not shown). We also determined nuclear DNA fragmentation as a sign of apoptosis in infected fibroblasts and macrophages using a terminal deoxynucleotidyltransferase-mediated dUTP-biotin nick-end-labeling (TUNEL) assay (Figure 2c and d). However, this assay was difficult to employ because infected cells do not die synchronously, and dead cells eventually disintegrate and detach, making them unavailable for analysis. Even though the TUNEL assay considerably underestimates the true percentage of dead cells, the results were basically concordant with the results of the cell viability assay (Figure 2a and $b$ ).

A strong activation of caspase- 3 was detected in fibroblasts and macrophages infected with the $\Delta \mathrm{m} 41$ or the m41.1ko mutant (Figure 2e and f). By contrast, caspase-3 activation was largely suppressed in cells infected with $\mathrm{m} 41.1$ - or M11Lexpressing MCMVs. Taken together these results suggested that $\mathrm{m} 41.1$ is a potent inhibitor of infection-induced apoptosis. Under the conditions tested here, m41 was only a weak celldeath suppressor, whose activity became apparent primarily in macrophages.

We then infected fibroblasts and macrophages with the different viruses and analyzed viral replication after infection with low MOI. Multistep replication kinetics in 10.1 fibroblasts and RAW264.7 macrophages indicated that viral replication in fibroblasts is largely unaffected by the absence of $\mathrm{m} 41 \mathrm{and} / \mathrm{or}$ m41.1 (Figure 2g), but is severely impaired in macrophages in the absence of $\mathrm{m} 41.1$ (Figure $2 \mathrm{~h}$ ).

The m41.1 protein localizes to mitochondria and
protects infected cells from drug-induced apoptosis. The observation that the loss of $m 41.1$ could be compensated by inserting the Bcl- $\mathrm{x}_{\mathrm{L}}$ or the M11L gene into the MCMV genome (Figure 2) suggested that $\mathrm{m} 41.1$ might function in a similar way and inhibit apoptosis at the mitochondrial checkpoint. To determine the localization of the m41.1 protein, we transfected cells with a plasmid expressing $\mathrm{m} 41.1$ with a C-terminal HA tag and analyzed its localization by immunofluorescence. As shown in Figure 3a, the $\mathrm{m} 41.1$ protein colocalized with the mitochondrial marker Hsp60 and with the mitochondrion-specific dye, MitoTracker, but did not colocalize with an endoplasmic reticulum (ER) marker. The m41.1 protein also displayed mitochondrial localization in MCMV-infected cells (Figure 3b).

Next we tested whether m41.1 protects infected cells from exogenous proapoptotic stimuli. To this end, fibroblasts were infected with wt and mutant MCMVs, and treated with the drugs staurosporine (STS) or actinomycin-D (ActD), both of which activate the mitochondrial apoptosis pathway. Indeed, 
a

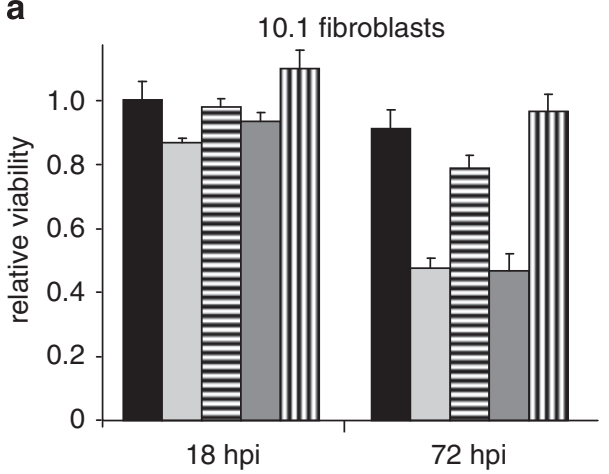

C

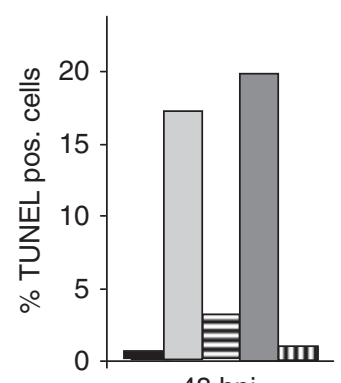

e

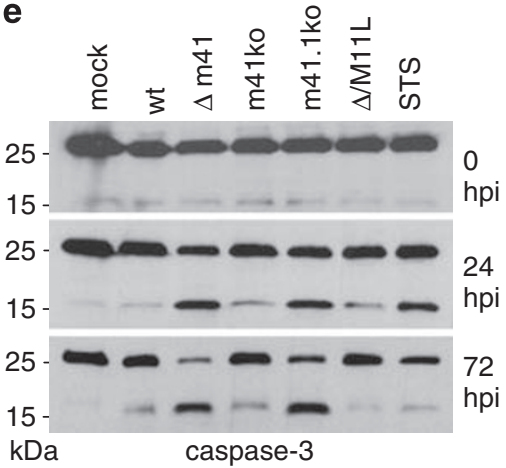

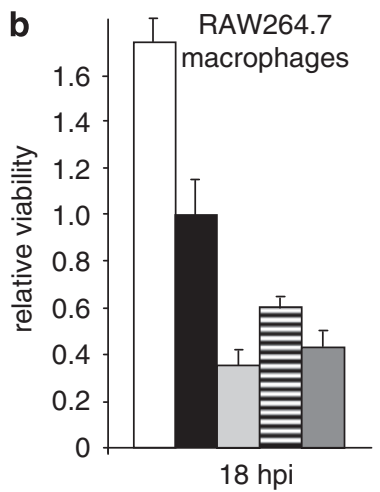

d

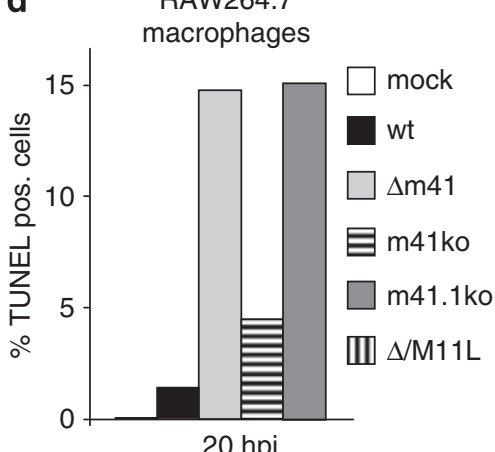

f
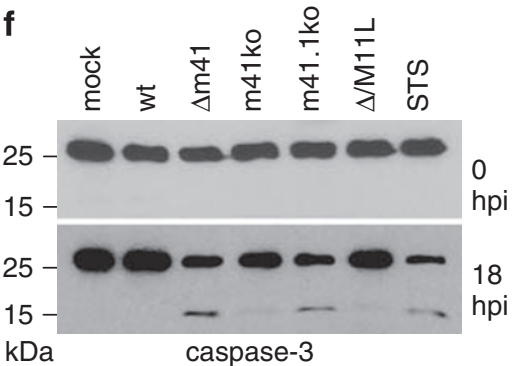

$\mathrm{kDa}$
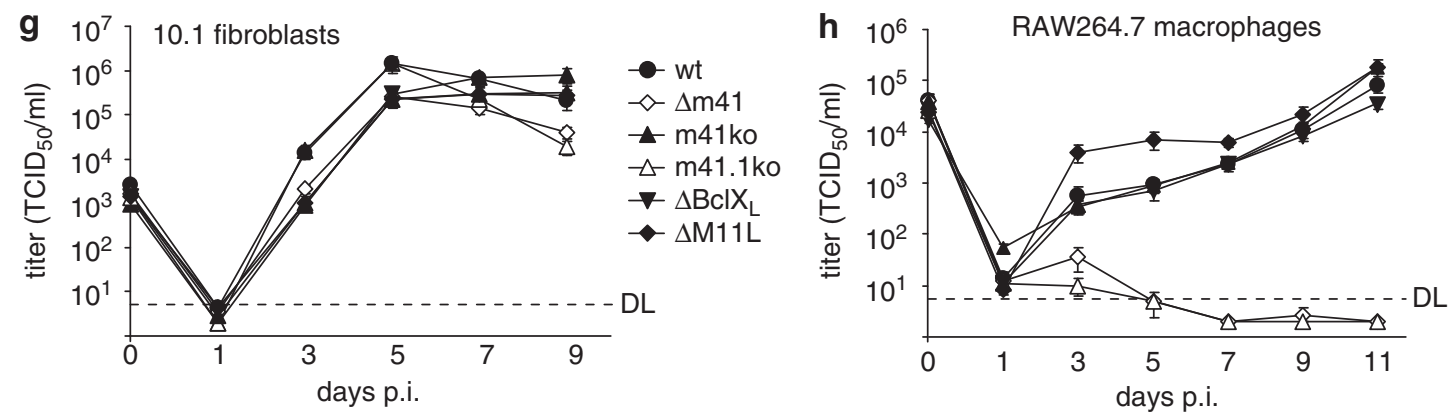

Figure 2 Phenotypic characterization of the mutant viruses. (a) 10.1 fibroblasts were infected at an MOI of 5 with wt or mutant MCMVs. Cell viability was measured using an MTT assay and values are shown relative to the viability of wt MCMV-infected cells. (b) RAW264.7 macrophages were infected at an MOI of 10 and cell viability was measured as above. (c, d) Nuclear DNA fragmentation was measured in infected fibroblasts and macrophages by TUNEL assay. (e, f) Caspase-3 activation was determined in the same cells by Western blotting using an anti-caspase- 3 antibody. The upper band represents the inactive procaspase-3 and the lower band represents the activated (cleaved) form. STS-treated cells are used as positive control. Note that the effect of STS has waned at $72 \mathrm{hpi} .(\mathbf{g}, \mathbf{h})$ To determine the replication capacities of the mutant viruses, 10.1 fibroblasts and RAW264.7 macrophages were infected at an $\mathrm{MOI}$ of 0.05 and 0.5 respectively. Viral replication was determined by titration on different days post-infection. DL, detection limit

deletion of m41.1 sensitized infected cells to STS and ActD (Figure 4a). We also treated infected cells with STS and tested whether m41.1 was required to inhibit mitochondrial cyt $c$ release. The results in Figure $4 b$ show that cyt $c$ release was inhibited in the presence of $m 41.1$. The lack of $m 41.1$ was compensated by expression of $\mathrm{Bcl}-\mathrm{x}_{\mathrm{L}}$ or M11L.

m41.1 specifically inhibits Bak-mediated cell death and synergizes with m38.5. Recently, we and others have shown that MCMV expresses a mitochondrial protein that specifically blocks Bax-mediated cell death. ${ }^{20,21,23}$ We further showed that Bax-knockout cells infected with an m38.5-deficient MCMV mutant $(\Delta \mathrm{m} 38.5)$ were resistant to
STS-induced apoptosis, suggesting that Bak-mediated apoptosis was inhibited by a different MCMV protein. ${ }^{20}$ To test whether m41.1 inhibits apoptosis in a Bak-specific manner, we infected fibroblasts deficient for Bax, Bak, or both proteins with different MCMV mutants and analyzed their sensitivity to STS. For comparison, we also included the previously described $\Delta$ m38.5 mutant and constructed a double-knockout (dko) mutant lacking both m41.1 and m38.5. The results shown in Figure 5 a clearly demonstrated that m41.1 was required to inhibit Bakmediated cell death, whereas m38.5 was required to block Bax-mediated cell death. In the absence of both m41.1 and m38.5, infected cells were sensitive to Bax- and 

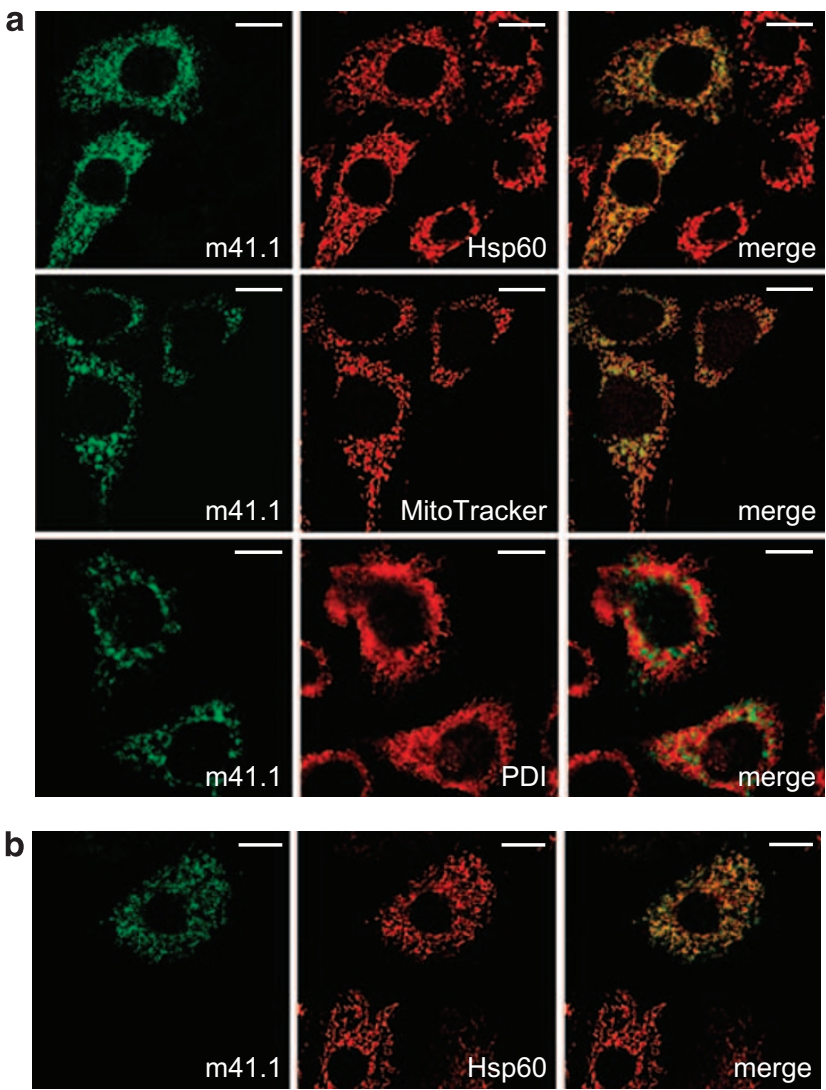

Figure 3 Fluorescence images showing mitochondrial localization of $\mathrm{m} 41.1$ (a) NIH-3T3 cells were transfected with a plasmid expressing HA-tagged m41.1. The protein was detected by immunofluorescence using an anti-HA antibody. The mitochondrial Hsp60 protein and the ER marker PDI were detected with specific antibodies. The red fluorescent MitoTracker dye was used to stain mitochondria. (b) Colocalization of m41.1 and Hsp60 was also detected in NIH-3T3 cells $10 \mathrm{hpi}$ with MCMV-m41.1HA. Bar, $10 \mu \mathrm{m}$

Bak-mediated apoptosis. Similar results were obtained without STS treatment, when the infection was allowed to proceed for a longer period of time (Figure $5 b$ ). This indicated that the viral infection itself leads to an induction of Bak- and Bax-mediated cell death.

The use of viral deletion mutants allowed us to determine that $\mathrm{m} 41.1$ is required for inhibition of Bak-dependent apoptosis. However, it was not clear from these results whether m41.1 by itself is sufficient to block Bak-dependent apoptosis. Therefore, we expressed $\mathrm{m} 41.1 \mathrm{in} \mathrm{Bak}^{+} / \mathrm{Bax}^{-}$and $\mathrm{Bak}^{-} / \mathrm{Bax}^{+}$fibroblasts by retroviral transduction and analyzed the sensitivity of the cells to drug-induced apoptosis. Indeed, m41.1 provided protection against STS- or ActDinduced apoptosis in Bak-only but not in Bax-only cells (Figure $5 \mathrm{c}-\mathrm{e})$. By contrast, Bcl- $\mathrm{X}_{\mathrm{L}}$ inhibited drug-induced apoptosis in both cell types, consistent with its known ability to inhibit Bak- and Bax-mediated cell death. ${ }^{26,27}$ In NIH-3T3 cells (which express both Bax and Bak), transfection of an m41.1 expression plasmid was not sufficient to inhibit apoptosis induced by Fas stimulation. Transfection of plasmids encoding Bax inhibitors of MCMV (m38.5) or HCMV (UL37x1) did also not protect from Fas-induced cell death. However, when m41.1 was coexpressed with m38.5 or UL37x1, Fas-induced

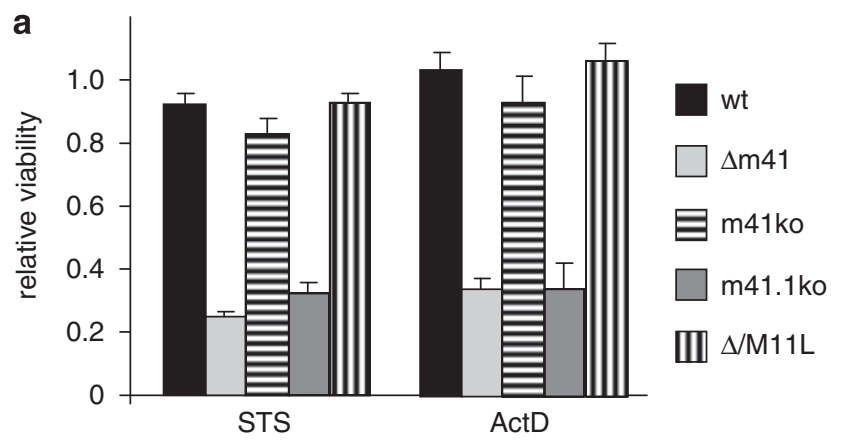

b

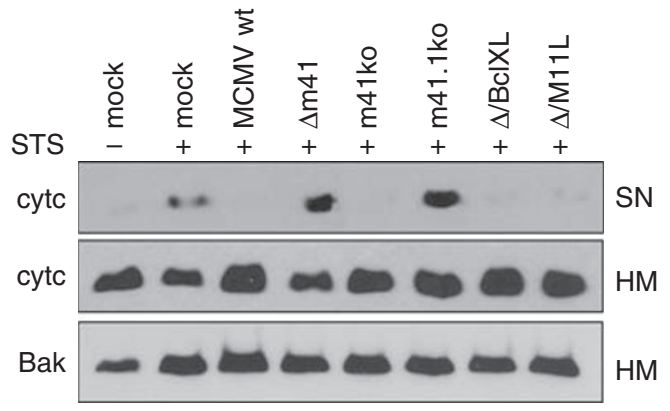

Figure $4 \mathrm{~m} 41.1$ is required to protect MCMV-infected cells from STS- or ActDinduced apoptosis. (a) Infected 10.1 fibroblasts were treated $6 \mathrm{hpi}$ with STS or ActD to induce apoptosis. Cell viability was determined $18 \mathrm{~h}$ later by MTT assay and is shown as relative viability compared with infected cells treated with the solvent DMSO. (b) Infected 10.1 fibroblasts were treated with STS and presence of cyt $c$ in the heavy membrane (HM) and supernatant (SN) fractions was determined by immunoblotting. Bak was used as a loading control for the HM fraction

apoptosis was inhibited to a similar extent as with $\mathrm{Bcl}-\mathrm{x}_{\mathrm{L}}$ (Figure 5f). These results confirmed that $\mathrm{m} 41.1$ and $\mathrm{m} 38.5$ synergize to inhibit Bak- and Bax-mediated cell death.

m41.1 interacts with Bak and inhibits Bak oligomerization. During activation of the mitochondrial apoptosis pathway, Bax and Bak undergo a conformational change leading to exposure of their N-terminus. In this open (activated) conformation, Bak and Bax molecules can oligomerize within the mitochondrial outer membrane. ${ }^{4}$ This leads to increased mitochondrial membrane permeability and release of proapoptotic factors such as cyt $c$. As the previous experiments had shown that $\mathrm{m} 41.1$ blocks cyt $c$ release, we wondered whether the preceding activation and oligomerization of Bak were also inhibited.

Bak activation can be assessed by immunofluorescence analysis using an antibody directed against the $\mathrm{N}$-terminus of $\mathrm{Bak}^{28}$ or against the Flag epitope if an N-terminally Flagtagged Bak is used. As shown in Figure 6a, MCMV infection induced Bak activation regardless of the presence or absence of m41.1. However, m41.1 itself is not responsible for Bak activation, because Bak is activated in cells infected with the $\mathrm{m} 41.1 \mathrm{ko}$ virus, and $\mathrm{m} 41.1$ expression from a plasmid vector does not induce the active conformation. Hence, m41.1 does not prevent Bak activation, and neither does $\mathrm{Bcl}-\mathrm{x}_{\mathrm{L}}$ (Figure 6a). It is known that $\mathrm{Bcl}-\mathrm{x}_{\mathrm{L}}$ and $\mathrm{Mcl}-1$ interact with Bak in its open (active) conformation, ${ }^{29}$ whereas VDAC2 interacts with the closed conformation. ${ }^{30}$ Thus, m41.1 might 

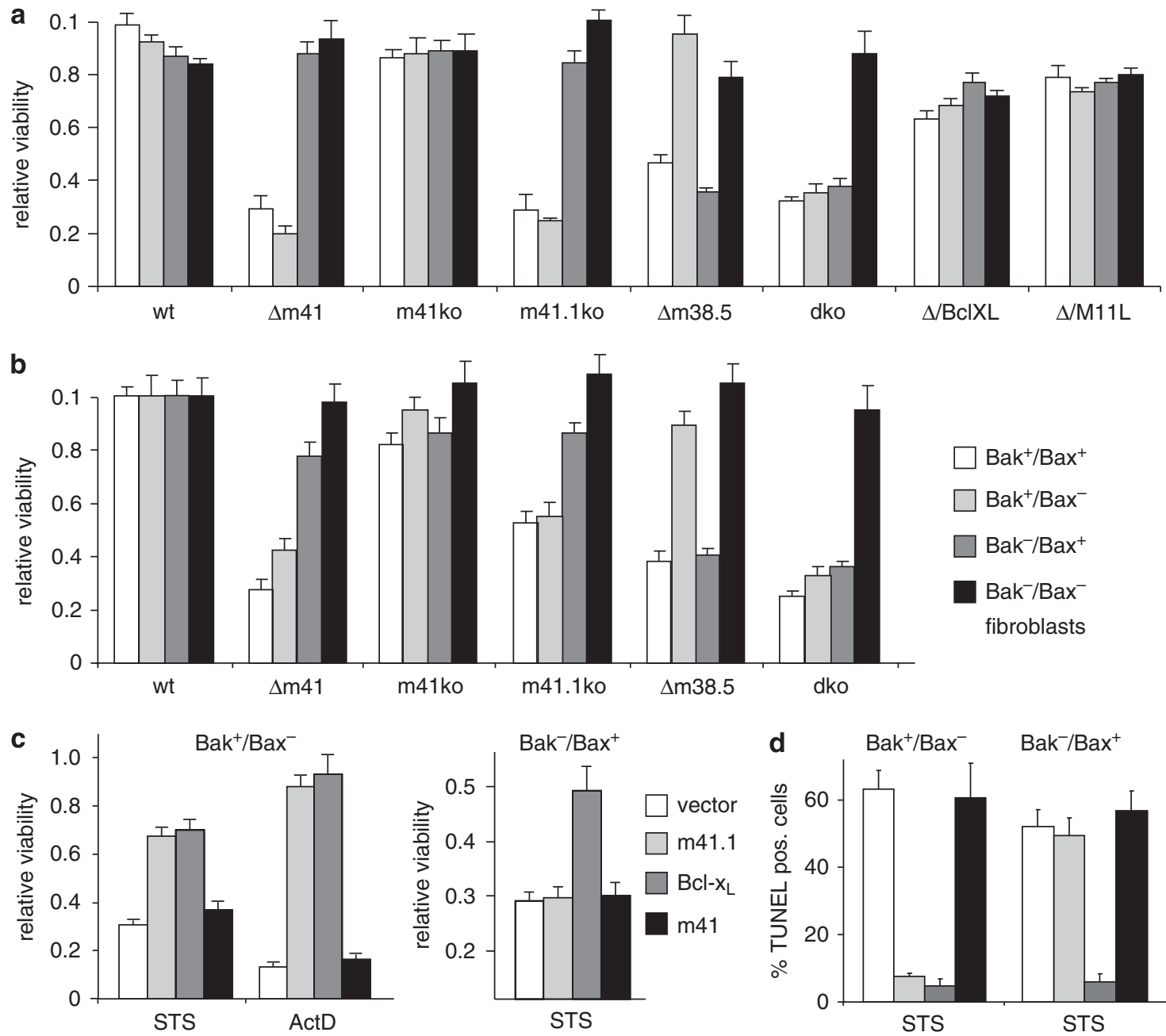

e

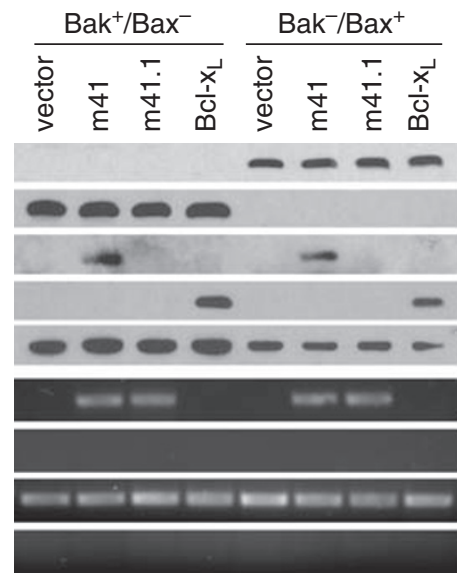

f

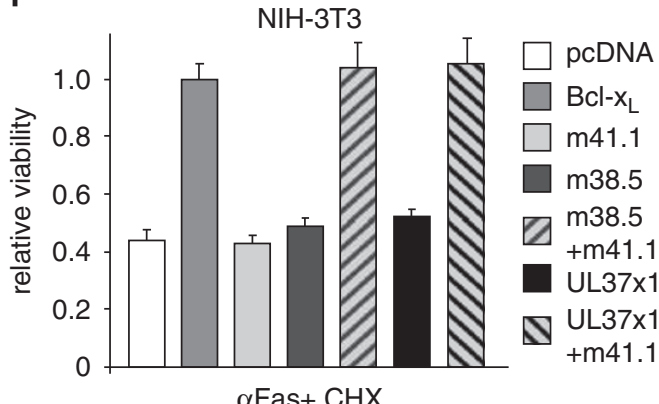

Figure 5 Bak-specific inhibition of apoptosis by $\mathrm{m41.1}$ and synergy with the Bax-specific inhibitor vMIA. (a) Wt fibroblasts and fibroblasts lacking Bax and/or Bak were infected at an MOI of 5 with wt and mutant MCMVs as indicated. Six hpi cells were treated with STS for $24 \mathrm{~h}$. Cell viability relative to DMSO-treated control cells was determined by MTT assay. (b) Cells were infected as described in panel a, but were not treated with STS. Cell viability at 70 hpi is shown relative to wt MCMV-infected cells. (c) Fibroblasts expressing only Bak or only Bax were transduced with retroviral vectors encoding $\mathrm{m} 41, \mathrm{~m} 41.1$, or Bcl-x. Apoptosis was induced by treatment with STS or ActD. Cell viability was determined $48 \mathrm{~h}$ later and is shown relative to the DMSO-treated control cells. (d) Cells were transduced and treated with STS as in panel $\mathbf{c}$. Nuclear-DNA fragmentation was measured after $25 \mathrm{~h}$ by TUNEL assay. (e) The presence of the relevant proteins in the cells used in panel $\mathbf{d}$ was determined by immunoblotting using antibodies specific to Bax, Bak, and $\mathrm{m} 41$. HA-tagged $\mathrm{BCl}-\mathrm{x}_{\mathrm{L}}$ was detected with anti-HA antibody and tubulin served as loading control. Pilot experiments had indicated that the C-terminal HA tag reduces the antiapoptotic activity of $\mathrm{m} 41.1$, and, therefore, vectors expressing untagged $\mathrm{m} 41.1$ were used in all cell death assays. Expression of the untagged $\mathrm{m} 41.1$ and c-myc (as control) was determined by RT-PCR. Note that the m41.1 sequence is also PCR-amplified from $\mathrm{m} 41$ transcripts, as $\mathrm{m} 41.1$ lies within $\mathrm{m} 41$. However, the m41.1 ATGs were mutated to ACG in the m41 expression vector, and, therefore, $\mathrm{m} 41.1$ is not translated from the $\mathrm{m} 41$ transcript. (f) $\mathrm{NIH}-3 \mathrm{~T} 3$ fibroblasts were transfected with plasmids expressing the indicated proteins and treated with an anti-Fas antibody and cycloheximide (CHX) to induce apoptosis. Cell viability was determined by MTT assay and is shown relative to cells transfected with a BCl- $\mathrm{x}_{\llcorner}$expression plasmid 
inhibit Bak in a similar way as $\mathrm{Bcl}-\mathrm{x}_{\mathrm{L}}$. In support of this hypothesis, we found that $\mathrm{m} 41.1$ colocalized with activated Flag-Bak in MCMV-infected cells (Figure 6b).

a
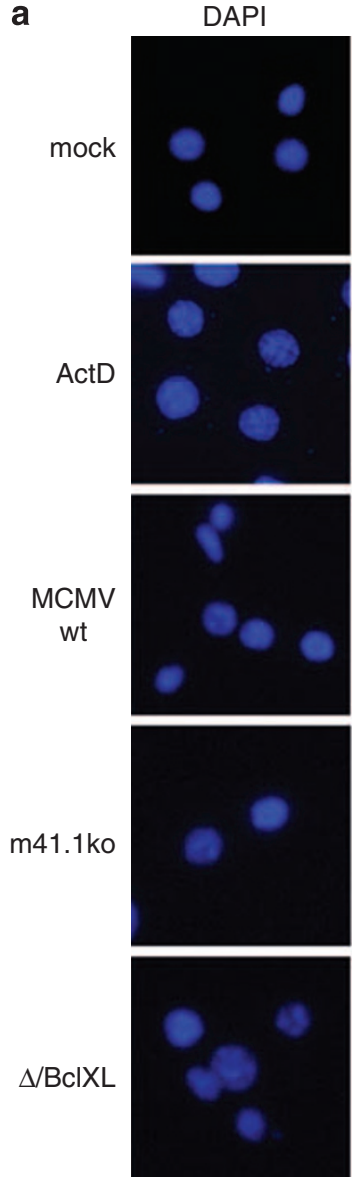

DAPI

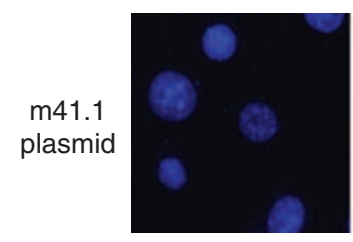

b
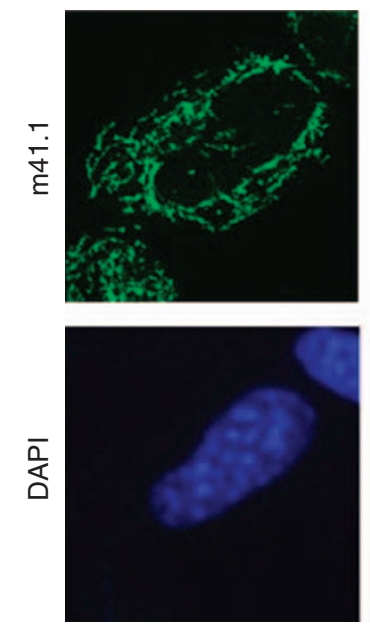

GFP
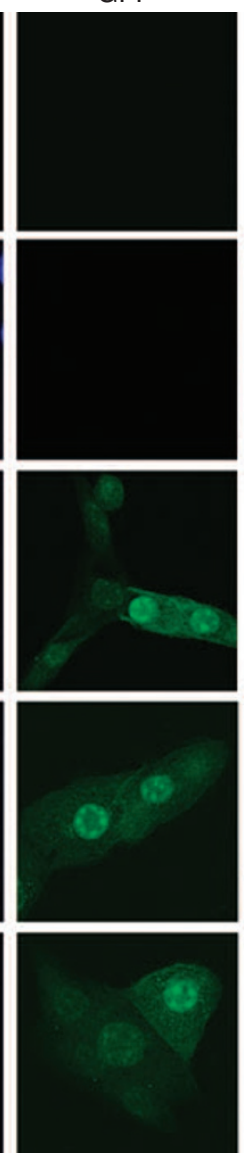

$\mathrm{m} 41.1$
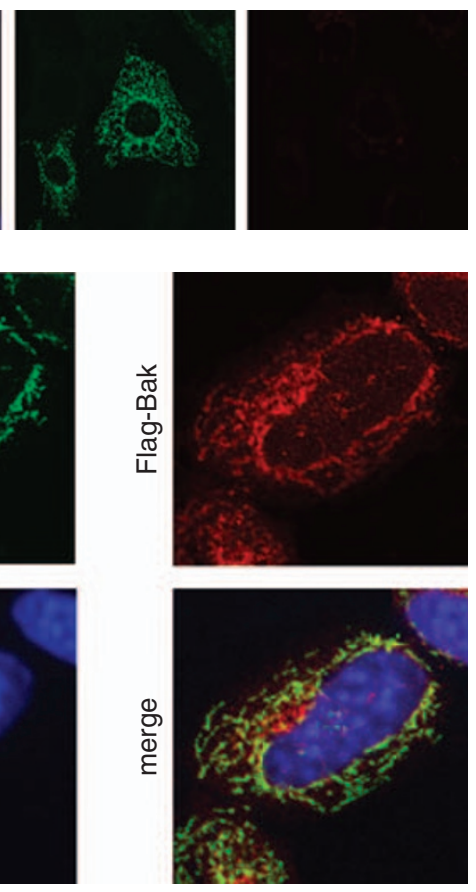

To test whether m41.1 interacts with Bak, we transfected HEK 293 cells with plasmids encoding Flag-Bak and HAtagged m41.1 or m41, respectively. As shown in Figure 7a, m41.1 co-immunoprecipitated with Bak and vice versa, but $\mathrm{m} 41$ did not. This indicated a direct or indirect interaction of m41.1 and Bak.

To determine the influence of m41.1 on Bak oligomerization, we infected fibroblasts expressing Bak (but not Bax) with wt and mutant MCMVs, stimulated the mitochondrial apoptosis pathway with STS, and then stabilized oligomeric complexes by adding the crosslinker $1^{\prime}, 6^{\prime}$-bismaleimidohexane $(\mathrm{BMH})$. As shown in Figure $7 \mathrm{~b}$, Bak oligomerization was inhibited by MCMV only if the virus expressed m41.1 or Bcl- $x_{L}$. Similarly, m41.1 inhibited Bak oligomerization in MCMV-infected cells expressing Bak and Bax (Supplementary Figure S3), suggesting that m41.1 inhibits both homo- and heterooligomerization of Bak. STS-induced Bak oligomerization was also inhibited by $\mathrm{m} 41.1$ or $\mathrm{Bcl}-\mathrm{x}_{\mathrm{L}}$ alone in transduced cells (Figure $7 \mathrm{c}$ ). Hence we concluded that the $\mathrm{m} 41.1$ protein functions as a viral inhibitor of Bak oligomerization (vIBO).

Evolutionary conservation of $\mathbf{m} 41.1$. HCMV expresses a Bax-specific mitochondrial inhibitor of apoptosis (VMIA) that is conserved in primate CMVs. ${ }^{31}$ Rodent CMVs also express VMIA proteins, but there is no apparent sequence similarity between primate and rodent VMIAs. ${ }^{19}$ When we searched all available CMV sequences for the presence of putative m41.1 homologs, we identified ORFs encoding highly similar proteins in two rat CMVs, the Maastricht and the English isolates (Figure 8a). The ORFs are located at analogous positions within the viral genomes and were named r41.1 and e41.1, respectively. By contrast, we did not detect ORFs similar to m41.1 in human or other primate CMVs.

To test whether sequence conservation correlated with functional conservation, we analyzed the function of the e41.1 protein of the rat CMV (RCMV) English isolate. Indeed, the e41.1 protein localized to mitochondria (Figure $8 \mathrm{~b}$ ) and inhibited ActD-induced apoptosis in $\mathrm{Bak}^{+} / \mathrm{Bax}^{-}$cells (Figure $8 \mathrm{c}$ ), suggesting that the function of $\mathrm{m} 41.1 / \mathrm{vlBO}$ is conserved among rodent CMVs.

\section{Discussion}

In this study, we identified a new viral antiapoptotic protein that inhibits apoptosis induced by cytotoxic drugs or by the viral infection itself in a Bak-dependent manner. We further showed that this Bak-specific inhibitor synergizes with a previously identified Bax-specific inhibitor to protect infected cells from apoptosis-inducing stimuli.

The m41.1 protein is an unusual apoptosis inhibitor as it differs in many ways from known viral Bcl-2-like proteins:

Figure 6 Bak activation by MCMV infection. (a) NIH-3T3 cells were infected with wt or mutant MCMVs, all of which express GFP. Activated Bak was detected by immunofluorescence using an antibody directed against the Bak N-terminus. Bak is inactive in mock-infected cells and in cells transfected with pcDNA-m41.1HA. Activated Bak is detected after treatment with $10 \mu \mathrm{g} / \mathrm{ml}$ ActD for $10 \mathrm{~h}$. (b) Cells stably expressing Flag-Bak were infected with MCMV-m41.1HA. Cells were fixed $10 \mathrm{hpi}$, stained with anti-HA and anti-Flag antibodies, and analyzed by confocal microscopy 

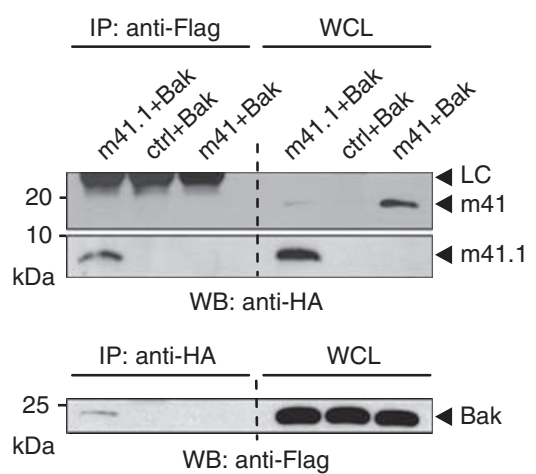

b

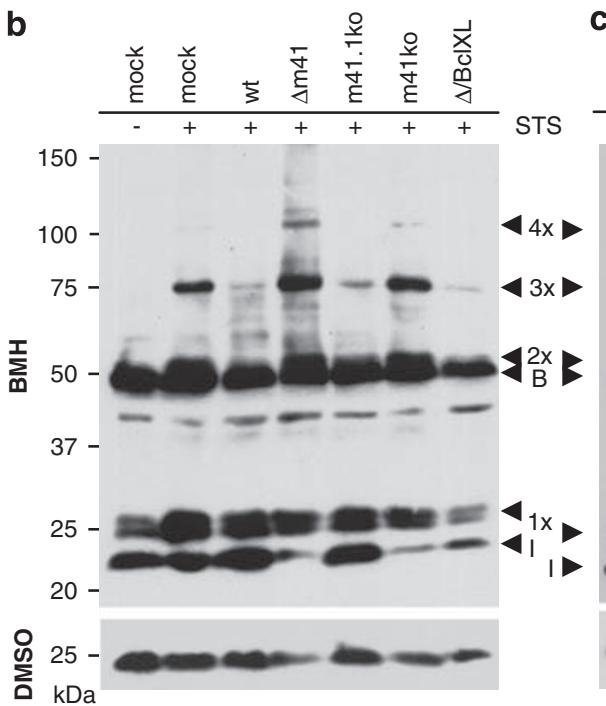

C

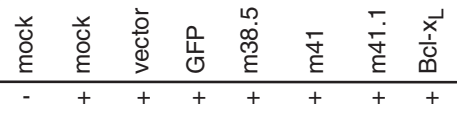

$-150$

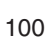

75

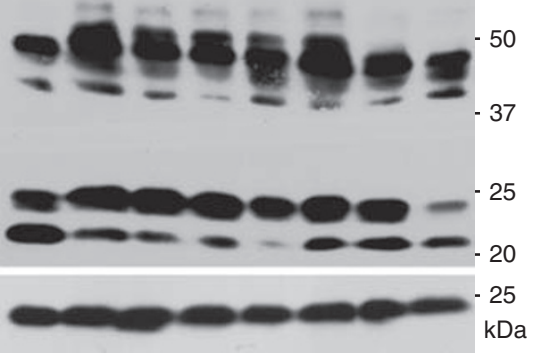

Figure 7 Interaction with Bak and inhibition of Bak oligomerization by m41.1. (a) HEK 293 cells were co-transfected with plasmids expressing Flag-tagged Bak and HA-tagged m41.1, m41, or a control (ctrl) plasmid. Whole-cell lysates (WCL) were subjected to immunoprecipitation (IP) using either an anti-HA or an anti-Flag antibody. The co-immunoprecipitated proteins were detected by Western blotting (WB). LC indicates the antibody light chain. (b) Fibroblasts stably expressing Flag-Bak (but not Bax) were infected with wt and mutant MCMVs, and treated with STS to enhance Bak oligomerization. Cell lysates were treated with DMSO or the crosslinking agent BMH for 30 min, separated by gel electrophoresis, and probed with an anti-Flag antibody. Mono-, di-, tri-, and tetrameric complexes are indicated with arrow heads $(1 \times$ to $4 \times)$. I indicates a faster migrating, internally crosslinked Bak isoform. B probably represents Bak crosslinked to a different cellular protein. (c) Fibroblasts expressing Flag-Bak were transduced with retroviruses encoding the indicated proteins and treated with STS. Bak oligomerization was determined as described above
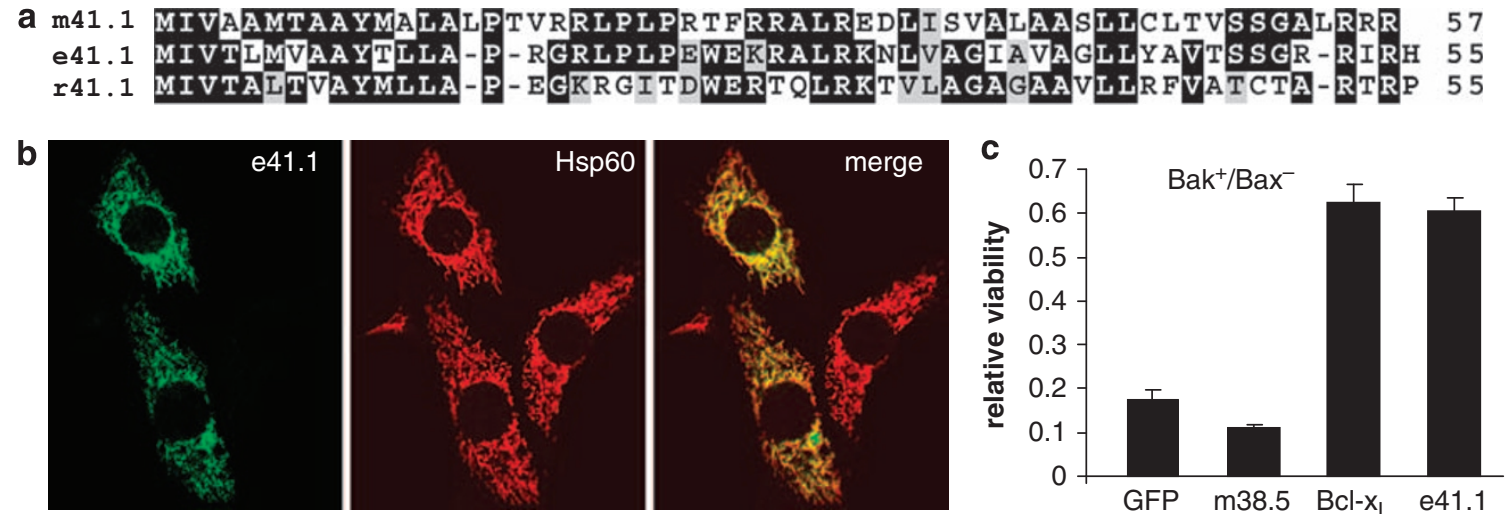

Figure 8 Evolutionary conservation of $m$ 41.1. (a) ClustalW amino-acid sequence alignment of MCMV protein m41.1, rat CMV English isolate protein e41.1, and rat CMV Maastricht isolate protein r41.1. Identical and similar amino acids are shaded in black and gray, respectively. (b) NIH-3T3 cells were transfected with a plasmid expressing HA-tagged e41.1. Colocalization of e41.1 with the mitochondrial protein Hsp60 was determined by confocal microscopy as in Figure 3. (c) Bak ${ }^{+} /$Bax $^{-}$fibroblasts were transduced with retroviral vectors expressing the indicated proteins and treated with ActD for $48 \mathrm{~h}$ as in Figure $5 \mathrm{c}$. Bcl- $\mathrm{x}_{\mathrm{L}}$ and e 41.1 protected from ActD-induced cell death, but m38.5 did not

(i) With 57 amino acids and a molecular mass of approximately $7 \mathrm{kDa}$, the $\mathrm{m} 41.1$ protein is much smaller than cellular and viral $\mathrm{Bcl}-2$ analogs; (ii) the m41.1 protein shows no recognizable sequence similarity to known antiapoptotic proteins and lacks $\mathrm{BH}$ domains characteristic of the cellular and viral Bcl-2-family proteins; and (iii) it is the first viral protein that specifically inhibits Bak- but not Bax-mediated cell death.

The small size of the m41.1 protein initially suggested that it could be an essential component of a larger viral protein complex acting at the mitochondrial checkpoint. Additional mitochondrial proteins of unknown function have recently been discovered in $\mathrm{MCMV},{ }^{32}$ and these might be part of such a complex. However, our subsequent results showed that the m41.1 protein is sufficient for inhibiting Bak oligomerization (Figure 7c) and Bak-mediated cell death (Figure 5c and d). Although we cannot exclude a role of the other MCMV mitochondrial proteins (e.g., for stabilizing or reinforcing the activity of m41.1 or m38.5), these proteins are clearly not essential for the functions of $\mathrm{m} 41.1 / \mathrm{vIBO}$ and $\mathrm{m} 38.5 / \mathrm{vMIA}$.

It might seem surprising that m41.1-negative MCMVs do not replicate in macrophages, although they grow with only minimal defects in fibroblasts (Figure $2 \mathrm{~g}$ and $\mathrm{h}$ ). The most likely reason for this is that macrophages are much more sensitive than fibroblasts to cell death induced by infection 
with m41.1-negative viruses. In macrophages, cell death occurs 15-24 h after infection with high $\mathrm{MOI}$, but in fibroblasts only after $48-72 \mathrm{~h}$ (Figure $2 \mathrm{a}-\mathrm{d}$ ). As the replication cycle of MCMV takes approximately $24 \mathrm{~h}$, the early onset of apoptosis in macrophages should massively impair virus progeny production. An increased sensitivity to infection-induced cell death and/or reduced viral replication in macrophages has also been observed with MCMVs lacking other cell-death suppressors such as $\mathrm{m} 38.5,{ }^{22} \mathrm{M} 36,{ }^{26}$ or $\mathrm{M} 45,{ }^{33}$ suggesting that macrophages are generally more sensitive to infectioninduced cell death.

Although widely used, the MTT assay has occasionally been criticized for relying on mitochondrial respiration as a measure of cell viability. This point was worth considering, as it has been shown that HCMV stabilizes mitochondrial respiration. ${ }^{33}$ Therefore, it is important to be sure that the MTT assay really measures the viability of MCMV-infected cells and does not merely reflect changes in mitochondrial respiration. We have obtained results very similar to the MTT assay results using a conventional Trypan blue exclusion assay (data not shown) and have also published similar results to those for the $\Delta \mathrm{m} 41$ mutant using a neutral red inclusion assay. ${ }^{24}$ Moreover, the results of the MTT assay were consistent with the results of two apoptosis assays (TUNEL and caspase-3 activation; Figure 2). Thus we concluded that the MTT assay is an adequate means to quantify cell viability in this study.

Mammalian cells express at least six antiapoptotic Bcl-2family proteins: $\mathrm{Bcl}-2, \mathrm{Bcl}-\mathrm{x}_{\mathrm{L}}, \mathrm{Bcl}-\mathrm{w}, \mathrm{Bcl}-\mathrm{B}, \mathrm{Bfl}-1 / \mathrm{A} 1$, and Mcl-1. Four of them interact with and inhibit both Bax- and Bak-, but Bcl-B predominantly blocks Bax-, and $\mathrm{Mcl}-1$ predominantly blocks Bak-mediated apoptosis. ${ }^{27}$ This finding has lent further support to the hypothesis that the numerous $\mathrm{Bcl}-2$ proteins exist because they serve at least some nonoverlapping functions and can be regulated independently in different cells and tissues. ${ }^{11}$ If correct, this hypothesis would imply that viral proteins with Bcl-2-like functions could also differentially modulate the proapoptotic proteins Bax and Bak. The present study demonstrates that this is being done by MCMV and related viruses.

The evolutionary origin of $\mathrm{m} 41.1 / \mathrm{vIBO}$ remains enigmatic. The protein shows no apparent sequence homology to any cellular gene and is, therefore, unlikely to be a gene captured from the host-cell genome, as it is assumed to be the case for the $\mathrm{Bcl}-2$ homologs of other viruses. It is unclear why CMVs have evolved their own antiapoptotic proteins instead of capturing them. However, CMVs have also taken their own path for inhibition of caspase-8 (a.k.a. FLICE): The UL36 and M36 proteins of HCMV and MCMV inhibit caspase- 8 activation, ${ }^{26,35}$ but share no homology with the cellular FLICE inhibitory proteins (cFLIPs) and the vFLIPs found in $\gamma$-herpesviruses and poxviruses. ${ }^{36}$

Orthologs of m41.1/vIBO are encoded by two RCMVs (Figure 8), and these viruses also encode orthologs of the Bax antagonist $338.5 .^{20}$ Hence, the principle of blocking Bax- and Bak-mediated cell death with two separate viral proteins seems to be conserved in these related viruses. HCMV expresses VMIA from ORF UL37x $1,{ }^{14}$ which is located at a genomic position analogous to $\mathrm{m} 38.5$, but shows no obvious sequence similarity to the MCMV gene. Orthologs of HCMV
VMIA were also found in a number of primate CMVs. ${ }^{31}$ It has been shown that HCMV VMIA interacts with Bax and inhibits Bax- but not Bak-mediated cell death. ${ }^{15,16,21}$ This suggests that human and primate CMVs might also express a yet to be identified Bak-specific inhibitor. Alternatively, it has been argued that Bax is dominant over Bak in human cells (but not in mouse cells), and that a Bax-specific inhibitor might suffice to prevent mitochondrial outer membrane permeabilization. ${ }^{15}$ This would explain why vMIA blocks apoptosis efficiently in human cells expressing Bax and Bak. However, another study challenged the Bax specificity of HCMV VMIA by presenting evidence that VMIA also interacts with Bak. ${ }^{37}$

Future studies will elucidate the similarities and differences in the way how primate and rodent CMVs inhibit Bax and Bak. Particularly the rodent CMVs provide an excellent model to study the role of Bax and Bak during viral infection and will help to reveal non-redundant functions of these two cellular apoptosis mediators.

\section{Materials and Methods}

Cells and viruses. IC-21 (ATCC TIB-186) and RAW264.7 (ATCC TIB-71) macrophages were grown in RPMI 1640 or DMEM supplemented with $10 \%$ FCS, and $10 \mathrm{mM} \mathrm{HEPES}$. Bak ${ }^{-1-}$ and $\mathrm{Bax}^{-1-}$ mouse fibroblast cell lines ${ }^{29}$ were provided by Georg Häcker (Technical University Munich, Germany), with permission from David Huang (WEHI, Melbourne, Australia). NIH-3T3 cells, 10.1 fibroblasts and HEK 293 cells were cultured as previously described. ${ }^{38}$ Wt and recombinant MCMVs were propagated in 10.1 mouse fibroblasts as described, ${ }^{38}$ and viral titers were determined using the $\mathrm{TCID}_{50}$ (median tissue culture infective dose) method.

Plasmids and retroviral vectors. ORFs $\mathrm{m} 41.1$ and e41.1 were PCRamplified and cloned in pcDNA3 (Invitrogen, Karlsruhe, Germany) with and without a C-terminal HA tag. The murine bak gene was excised from pBabe-Bak-IRES-GFP ${ }^{39}$ (kindly provided by Wei-Xing Zong, SUNY, Stony Brook, NY, USA) and inserted into pcDNA3-Flag. The Flag-tagged bak gene was subsequently inserted into pMSCVpuro (Clontech). A codon-optimized version of the myxoma virus M11L gene with an N-terminal Flag tag was synthesized by GeneArt (Regensburg, Germany). The m41.1 coding sequence and FlagM11L were inserted into pReplacer essentially as described.$^{38}$ Retroviral vector plasmids pRetroGFP, pRetro-Bcl- $\mathrm{X}_{\mathrm{L}}$, and pRetro-m38.5.have been described, ${ }^{20}$ and pRetro-m41, pRetro-m41.1, and pRetroe41.1 were constructed analogously. To exclude $m 41.1$ protein expression from the pRetro-m41 vector, the three potential m41.1 ATG start codons were changed to ACG.

Retroviruses were generated by transfecting retroviral vector plasmids into the Phoenix Ampho packaging cell line as described. ${ }^{24}$ Filtered supernatants were used for transduction of $b a k^{-1-}$ or $b_{a x}{ }^{-1-}$ fibroblasts. Transduced fibroblasts were maintained as bulk cultures without selection. Fibroblasts stably expressing Flag-

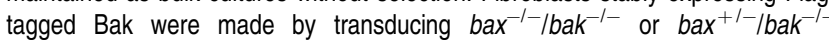
fibroblasts with MSCVpuro-Flag-Bak and selection with $4 \mu \mathrm{g} / \mathrm{ml}$ puromycin.

Recombinant MCMVs. All recombinant MCMVs are based on a GFPexpressing MCMV, except for MCMV-m41.1HA, which does not express GFP. The mutant viral genomes were constructed using the bacterial artificial chromosome (BAC) technology as described previously. ${ }^{24}$ An HA epitope sequence and a kan gene flanked by FLP recognition target (FRT) sequences were inserted at the $3^{\prime}$ end of the m41.1 ORF. MCMV $\Delta m 41$ has been described in reference. ${ }^{24}$ The $\Delta \mathrm{m} 41 / \mathrm{m} 41.1, \Delta \mathrm{m} 41 / \mathrm{Bcl}-\mathrm{X}_{\mathrm{L}}$, and $\Delta \mathrm{m} 41 / \mathrm{M} 11 \mathrm{~L}$ were obtained by inserting the indicated genes into the m02-m06 region of MCMV $\Delta \mathrm{m} 41$ using the pReplacer-based recombination system. ${ }^{38} \mathrm{An} \mathrm{m} 41$ coding sequence with the three potential ATG codons of m41.1 mutated to ACG was re-inserted into MCMV $\triangle \mathrm{m} 41$ with an FRT-kan-FRT cassette for selection. MCMV-m41.1ko was obtained after removal of the kan gene with FLP recombinase. Recombinant MCMV BACs were analyzed by restriction digest and by sequencing of the mutated site(s) (data not shown). BACs were transfected into 10.1 fibroblasts to reconstitute recombinant viruses. MCMV virion DNA was prepared essentially as described. ${ }^{40}$

RNA analyses. For Northern blot analysis, total cellular RNA was isolated with Trizol reagent (Invitrogen) and further purified with an RNeasy kit (Qiagen, Hilden, 
Germany) and subsequent DNAse-I (Roche, Mannheim, Germany) digestion. A $1-\mu \mathrm{g}$ weight of total RNA per sample was denatured, separated on a $1.2 \%$ denaturing agarose gel, and blotted onto a positively charged nylon membrane (Schleicher \& Schuell, Dassel, Germany). The RNA was crosslinked to the membrane using an UV crosslinker (Peqlab, Erlangen, Germany). Digoxigeninlabeled m41 RNA probes were synthesized with a DIG RNA Labeling kit (Roche) using linearized pcDNA-m $41^{24}$ as template for in vitro transcription with T7 or SP6 polymerase (Fermentas, St. Leon-Rot, Germany). Hybridization, washing, and detection of the DIG-labeled probe were performed according to the manufacturer's protocol (Roche).

Rapid amplification of $5^{\prime}$ and $3^{\prime}$ cDNA ends was performed with a SMART RACE kit (Clontech, Mountain View, CA, USA). Amplification products were cloned in pGEM-T Easy (Promega, Mannheim, Germany) and sequenced.

For reverse transcriptase (RT)-PCR analysis of gene expression, total cellular RNA was extracted and DNase-treated as described. ${ }^{41} \mathrm{C}$-myc transcripts were PCR amplified with published primers, ${ }^{41}$ and $\mathrm{m} 41.1$ transcripts with primers binding to the first and last $20 \mathrm{nt}$ of the m41.1 ORF.

Cell viability and apoptosis assays. STS and ActD were purchased from Sigma (Munich, Germany) and dissolved in DMSO at $500 \mu \mathrm{M}$ and $100 \mathrm{mg} / \mathrm{ml}$ concentrations, respectively. To induce cell death, MCMV-infected 10.1 cells were treated with $200 \mathrm{nM}$ STS or $250 \mathrm{ng} / \mathrm{ml} \mathrm{ActD}$. Infected, knockout MEFs were treated with $450 \mathrm{nM}$ STS. Retrovirus-transduced cells were treated $24 \mathrm{~h}$ after transduction with $425 \mathrm{nM}$ STS or $2 \mu \mathrm{g} / \mathrm{ml}$ ActD for $48 \mathrm{~h}$. NIH-3T3 cells grown in 48-well dishes were transfected with $0.7 \mu \mathrm{g}$ plasmid DNA using Superfect (Qiagen). Twenty-five hours after transfection, cells were treated with $0.5 \mu \mathrm{g} / \mathrm{ml}$ anti-Fas antibody (BD Pharmingen, San Diego, CA, USA) and $2.5 \mu \mathrm{g} / \mathrm{ml}$ cycloheximide for $45 \mathrm{~h}$. Cell viability was measured using an MTT assay as described. ${ }^{38}$ Absorbance at $570 \mathrm{~nm}$ was determined photometrically. Mean values and standard deviations of at least four parallel experiments are shown.

To analyze nuclear DNA fragmentation, 10.1 fibroblasts were grown and infected on coverslips. Transduced 10.1 cells were treated for $25 \mathrm{~h}$ with $600 \mathrm{nM}$ STS. Infected RAW264.7 were harvested from culture dishes and sedimented onto glass slides using Cytospin (Thermo Scientific, Waltham, MA, USA). Cells were fixed with $3 \%$ paraformaldehyde and stained with a terminal TUNEL assay kit (Roche) containing tetramethylrhodamine-coupled dUTP. Nuclei were counterstained with 4',6'-diamidino-2-phenylindole (DAPI). The TUNEL assay using transduced cells was performed in triplicate and more than 100 nuclei were evaluated per sample. For infected fibroblasts and macrophages, an average of 500 and 280 nuclei, respectively, in five or more randomly selected visual fields were counted.

To measure cyt $c$ release, $10^{6}$ cells were mock-infected or infected at an $\mathrm{MOI}$ of 3 . After $15 \mathrm{~h}$, cells were treated for $5 \mathrm{~h}$ with $450 \mathrm{nM}$ STS. Cells were harvested and separated into a mitochondria-enriched heavy membrane fraction and a supernatant fraction as described elsewhere. ${ }^{30}$

Bak oligomerization assay. Fibroblasts were infected at an $\mathrm{MOI}$ of 5 for $15 \mathrm{~h}$ and treated with $450 \mathrm{nM}$ STS for $5 \mathrm{~h}$. Bak oligomerization was determined as described elsewhere. ${ }^{42}$ Briefly, the mitochondria-enriched fraction was resuspended in HIM buffer $(200 \mathrm{mM}$ mannitol, $70 \mathrm{mM}$ sucrose, $10 \mathrm{mM}$ HEPES$\mathrm{KOH}, 1 \mathrm{mM}$ EGTA, pH 7.5) and freshly prepared 1', 6'-bismaleimidohexane (from TCl Europe, Zwijndrecht, Belgium) in DMSO was added to obtain a 2-mM final concentration. BMH-mediated crosslinking was allowed to proceed for $30 \mathrm{~min}$ at room temperature. Bak oligomerization in transduced cells was induced by $15 \mathrm{~h}$ incubation with $450 \mathrm{nM}$ STS.

Immunoprecipitation and immunoblotting. For immunoprecipitation experiments, $1.5 \times 10^{6} \mathrm{HEK} 293$ cells were co-transfected by calcium phosphate precipitation with pcDNAFlag-Bak and pcDNAm41.1HA, pcDNAm41HA, or a control plasmid. After $25 \mathrm{~h}$ cells were lysed in a buffer containing $150 \mathrm{mM} \mathrm{NaCl}$, $50 \mathrm{mM}$ Tris- $\mathrm{HCl}(\mathrm{pH} 7.5), 0.5 \%$ Triton-X-100, and a protease inhibitor cocktail (Roche). Flag- or HA-tagged proteins were precipitated at $4{ }^{\circ} \mathrm{C}$ overnight with antiFlag M2 (Sigma) or an anti-HA (Sigma) antibodies bound to protein-G or protein-A sepharose, respectively. Precipitates were washed six times with washing buffer $(100 \mathrm{mM} \mathrm{NaCl}, 20 \mathrm{mM}$ Tris (pH 7.5), $100 \mathrm{mM}$ EDTA, 0.05\% Tween-20) and eluted with boiling sample buffer. Cell lysates were separated by sodium dodecyl sulfatepolyacrylamide gel electrophoresis and transferred to nitrocellulose or PVDF membranes by semi-dry blotting following standard protocols. Anti-HA $16 \mathrm{~B} 12$ (Covance), anti- $\beta$-actin Ac74 (Sigma), anti- $\alpha$-tubulin (Santa Cruz Biotechnology, Santa Cruz, CA, USA), anti-Bak (Sigma), anti-Bax (Santa Cruz), anti-caspase-3
$8 \mathrm{G} 10$ (Cell Signaling), and anti-cyt $c$ (Santa Cruz) antibodies were purchased from suppliers as indicated. Antibodies against MCMV IE1 and E1 were provided by Stipan Jonjié (University of Rijeka, Croatia) and antibodies against M44 and glycoprotein B were a gift from Lambert Loh (University of Saskatchewan, Canada). Analysis of immediate-early, early, and late gene expression was performed as described previously. ${ }^{20}$ A sequence encoding amino acids $1-116$ of $m 41$ was cloned in pMAL-C2 (New England Biolabs, Frankfurt, Germany) that expresses maltose-binding protein (MBP). The MBP fusion protein was expressed in Escherichia coli and purified using an amylose resin column (New England Biolabs). Mice were immunized with the fusion protein and monoclonal antibodies were produced according to standard procedures. Note that the m41-specific $2 \mathrm{A6}$ antibody does not recognize m41.1, since the amino-acid sequences of the two proteins are unrelated (Figure 1a).

Immunofluorescence. Cells were seeded on coverslips at least $24 \mathrm{~h}$ prior to infection or transfection. Mitochondria were stained with $100 \mathrm{nM}$ MitoTracker Red CMXRos (Invitrogen) for $20 \mathrm{~min}$ at $37^{\circ} \mathrm{C}$. Cells were washed with PBS and fixed with $3 \%$ paraformaldehyde for $20 \mathrm{~min}$ at $4{ }^{\circ} \mathrm{C}$, neutralized with $50 \mathrm{mM}$ ammonium chloride, permeabilized with $0.3 \%$ Triton $\mathrm{X}-100$, and blocked with $0.2 \%$ gelatin. Proteins of interest were detected with primary antibodies against HA (3F10; Roche), Flag (M2; Sigma), Hsp60 (clone 24; BD Pharmingen), PDI (1D3; Stressgen, Ann Arbor, MI, USA), or the Bak N-terminus (TC-102; Calbiochem, Nottingham, UK), and secondary antibodies coupled to AlexaFluor568 or AlexaFluor488 (Invitrogen), respectively. Confocal laser-scanning microscopy was performed using a Zeiss LSM510 META microscope.

Database accession numbers. Sequences of $m 41.1$, r41.1, and e41.1 have been deposited at GenBank under the accession numbers FJ477245, FJ477244, and FJ477243, respectively.

Acknowledgements. We thank Georg Häcker, David Huang, and Wei-Xing Zong for providing cells and plasmids; Bernhard Nieswandt for help with monoclonal antibody production; Aline Pehla, Matthias Budt, and Kazimierz Madela for technical assistance; and Uwe Schumacher, Sebastian Voigt, and Kemuel-Noel Masihi for critically reading the manuscript. This work was supported by DFG grant BR 1730/3-1 to WB.

1. Everett H, McFadden G. Apoptosis: an innate immune response to virus infection. Trends Microbiol 1999; 7: 160-165.

2. Galluzzi L, Brenner C, Morselli E, Touat Z, Kroemer G. Viral control of mitochondrial apoptosis. PLoS Pathogens 2008; 4: e1000018.

3. Youle RJ, Strasser A. The BCL-2 protein family: opposing activities that mediate cell death. Nat Rev Mol Cell Biol 2008; 9: 47-59.

4. Chipuk JE, Green DR. How do BCL-2 proteins induce mitochondrial outer membrane permeabilization? Trends Cell Biol 2008; 18: 157-164.

5. Wei MC, Zong WX, Cheng EH, Lindsten T, Panoutsakopoulou V, Ross AJ et al. Proapoptotic BAX and BAK: a requisite gateway to mitochondrial dysfunction and death Science 2001; 292: 727-730.

6. Lindsten T, Ross AJ, King A, Zong WX, Rathmell JC, Shiels HA et al. The combined functions of proapoptotic Bcl-2 family members bak and bax are essential for normal development of multiple tissues. Mol Cell 2000; 6: 1389-1399.

7. Cartron PF, Juin P, Oliver L, Martin S, Meflah K, Vallette FM. Nonredundant role of Bax and Bak in Bid-mediated apoptosis. Mol Cell Biol 2003; 23: 4701-4712.

8. Kepp O, Rajalingam K, Kimmig S, Rudel T. Bak and Bax are non-redundant during infection- and DNA damage-induced apoptosis. EMBO J 2007; 26: 825-834.

9. Brooks $C$, Wei $Q$, Feng $L$, Dong G, Tao $Y$, Mei $L$ et al. Bak regulates mitochondrial morphology and pathology during apoptosis by interacting with mitofusins. Proc Natl Acad Sci USA 2007; 104: 11649-11654

10. Neise D, Graupner V, Gillissen BF, Daniel PT, Schulze-Osthoff K, Janicke RU et al. Activation of the mitochondrial death pathway is commonly mediated by a preferential engagement of Bak. Oncogene 2008; 27: 1387-1396.

11. Hardwick JM, Bellows DS. Viral versus cellular BCL-2 proteins. Cell Death Differ 2003; 10 (Suppl 1): S68-S76.

12. Kvansakul M, van Delft MF, Lee EF, Gulbis JM, Fairlie WD, Huang DC et al. A structural viral mimic of prosurvival $\mathrm{Bcl}-2$ : a pivotal role for sequestering proapoptotic Bax and Bak. Mol Cell 2007; 25: 933-942.

13. Kvansakul M, Yang H, Fairlie WD, Czabotar PE, Fischer SF, Perugini MA et al. Vaccinia virus anti-apoptotic $\mathrm{F} 1 \mathrm{~L}$ is a novel Bcl-2-like domain-swapped dimer that binds a highly selective subset of BH3-containing death ligands. Cell Death Differ 2008; 15: 1564-1571.

14. Goldmacher VS, Bartle LM, Skaletskaya A, Dionne CA, Kedersha NL, Vater CA et al. A cytomegalovirus-encoded mitochondria-localized inhibitor of apoptosis structurally unrelated to Bcl-2. Proc Natl Acad Sci USA 1999; 96: 12536-12541. 
15. Arnoult D, Bartle LM, Skaletskaya A Poncet D, Zamzami N, Park PU et al Cytomegalovirus cell death suppressor vMIA blocks Bax- but not Bak-mediated apoptosis by binding and sequestering Bax at mitochondria. Proc Natl Acad Sci USA 2004; 101: 7988-7993.

16. Poncet $D$, Larochette N, Pauleau AL, Boya $P$, Jalil AA, Cartron PF et al. An antiapoptotic viral protein that recruits Bax to mitochondria. J Biol Chem 2004; 279: 22605-22614.

17. Pauleau AL, Larochette N, Giordanetto F, Scholz SR, Poncet D, Zamzami N et al. Structure - function analysis of the interaction between Bax and the cytomegalovirus-encoded protein vMIA. Oncogene 2007; 26: 7067-7080.

18. Brocchieri L, Kledal TN, Karlin S, Mocarski ES. Predicting coding potential from genome sequence: application to betaherpesviruses infecting rats and mice. $J$ Virol 2005; 79 : 7570-7596.

19. McCormick AL, Meiering CD, Smith GB, Mocarski ES. Mitochondrial cell death suppressors carried by human and murine cytomegalovirus confer resistance to proteasome inhibitor-induced apoptosis. J Virol 2005; 79: 12205-12217.

20. Jurak I, Schumacher U, Simic H, Voigt S, Brune W. Murine cytomegalovirus m38.5 protein inhibits Bax-mediated cell death. J Virol 2008; 82: 4812-4822.

21. Arnoult D, Skaletskaya A, Estaquier J, Dufour C, Goldmacher VS. The murine cytomegalovirus cell death suppressor m38.5 binds Bax and blocks Bax-mediated mitochondrial outer membrane permeabilization. Apoptosis 2008; 13: 1100-1110.

22. Manzur M, Fleming P, Huang DC, Degli-Esposti MA, Andoniou CE. Virally mediated inhibition of Bax in leukocytes promotes dissemination of murine cytomegalovirus. Cell Death Differ 2009; 16: 312-320.

23. Norris KL, Youle RJ. Cytomegalovirus proteins VMIA and $\mathrm{m} 38.5$ link mitochondria morphogenesis to Bcl-2 family proteins. J Virol 2008; 82: 6232-6243.

24. Brune W, Nevels $M$, Shenk T. Murine cytomegalovirus $m 41$ open reading frame encodes a Golgi-localized antiapoptotic protein. J Virol 2003; 77: 11633-11643.

25. Everett H, Barry M, Lee SF, Sun X, Graham K, Stone J et al. M11L: a novel mitochondrialocalized protein of myxoma virus that blocks apoptosis of infected leukocytes. J Exp Med 2000; 191: 1487-1498

26. Ménard C, Wagner M, Ruzsics Z, Holak K, Brune W, Campbell A et al. Role of murine cytomegalovirus US22 gene family members for replication in macrophages. J Virol 2003; 77: 5557-5570.

27. Zhai D, Jin C, Huang Z, Satterthwait AC, Reed JC. Differential regulation of Bax and Bak by antiapoptotic Bcl-2 family proteins Bcl-B and Mcl-1. J Biol Chem 2008; 283: 9580-9586.

28. Arnoult $\mathrm{D}$. Apoptosis-associated mitochondrial outer membrane permeabilization assays. Methods 2008; 44: 229-234.
29. Willis SN, Chen L, Dewson G, Wei A, Naik E, Fletcher Jl et al. Proapoptotic Bak is sequestered by Mcl-1 and Bcl-xL, but not Bcl-2, until displaced by BH3-only proteins. Genes Dev 2005; 19: 1294-1305.

30. Cheng EH, Sheiko TV, Fisher JK, Craigen WJ, Korsmeyer SJ. VDAC2 inhibits BAK activation and mitochondrial apoptosis. Science 2003; 301: 513-517.

31. McCormick AL, Skaletskaya A, Barry PA, Mocarski ES, Goldmacher VS. Differential function and expression of the viral inhibitor of caspase 8-induced apoptosis (vICA) and the viral mitochondria-localized inhibitor of apoptosis (VMIA) cell death suppressors conserved in primate and rodent cytomegaloviruses. Virology 2003; 316: 221-233.

32. Tang $Q$, Murphy EA, Maul GG. Experimental confirmation of global murine cytomegalovirus open reading frames by transcriptional detection and partial characterization of newly described gene products. J Virol 2006; 80: 6873-6882.

33. Brune W, Ménard C, Heesemann J, Koszinowski UH. A ribonucleotide reductase homolog of cytomegalovirus and endothelial cell tropism. Science 2001; 291: 303-305.

34. Reeves MB, Davies AA, McSharry BP, Wilkinson GW, Sinclair JH. Complex I binding by a virally encoded RNA regulates mitochondria-induced cell death. Science 2007; 316: 1345-1348.

35. Skaletskaya A, Bartle LM, Chittenden T, McCormick AL, Mocarski ES, Goldmacher VS. A cytomegalovirus-encoded inhibitor of apoptosis that suppresses caspase-8 activation. Proc Natl Acad Sci USA 2001; 98: 7829-7834.

36. Thome M, Schneider P, Hofmann K, Fickenscher H, Meinl E, Neipel F et al. Viral FLICEinhibitory proteins (FLIPs) prevent apoptosis induced by death receptors. Nature 1997; 386: 517-521.

37. Karbowski M, Norris KL, Cleland MM, Jeong SY, Youle RJ. Role of Bax and Bak in mitochondrial morphogenesis. Nature 2006; 443: 658-662.

38. Jurak I, Brune W. Induction of apoptosis limits cytomegalovirus cross-species infection. EMBO J 2006; 25: 2634-2642.

39. Zong WX, Li C, Hatzivassiliou G, Lindsten T, Yu QC, Yuan J et al. Bax and Bak can localize to the endoplasmic reticulum to initiate apoptosis. J Cell Biol 2003; 162: 59-69.

40. Redwood AJ, Messerle M, Harvey NL, Hardy CM, Koszinowski UH, Lawson MA et al. Use of a murine cytomegalovirus K181-derived bacterial artificial chromosome as a vaccine vector for immunocontraception. J Virol 2005; 79: 2998-3008.

41. Voigt S, Mesci A, Ettinger J, Fine JH, Chen P, Chou W et al. Cytomegalovirus evasion of innate immunity by subversion of the NKR-P1B:Clr-b missing-self axis. Immunity 2007; 26: 617-627.

42. Ruffolo SC, Shore GC. BCL-2 selectively interacts with the BID-induced open conformer of BAK, inhibiting BAK auto-oligomerization. J Biol Chem 2003; 278: 25039-25045.

Supplementary Information accompanies the paper on Cell Death and Differentiation website (http://www.nature.com/cdd) 